\title{
Laparoscopic antireflux surgery increases health-related quality of life in children with GERD
}

\author{
Femke A. Mauritz ${ }^{1,3}$ (Debecca K. Stellato ${ }^{4}$ - L. W. Ernst van Heurn ${ }^{5}$. \\ Peter D. Siersema ${ }^{3} \cdot$ Cornelius E. J. Sloots $^{6} \cdot$ Roderick H. J. Houwen $^{2}$ • \\ David C. van der Zee ${ }^{1} \cdot$ Maud Y. A. van Herwaarden-Lindeboom ${ }^{1}$
}

Received: 4 May 2016/Accepted: 2 November 2016/Published online: 18 November 2016

(c) The Author(s) 2016. This article is published with open access at Springerlink.com

\begin{abstract}
Introduction Improving health-related quality of life (HRQoL) is increasingly recognized as an essential part of patient care outcome. Little is known about the effect of laparoscopic antireflux surgery (LARS) on the HRQoL in the pediatric patients. The aims of this study were to evaluate the effect of LARS on HRQoL in children with gastroesophageal reflux disease (GERD) and to identify predictors that influence HRQoL outcome after LARS.

Methods Between 2011 and 2013, 25 patients with therapy-resistant GERD [median age $6(2-18)$ years] were included prospectively. Caregivers and children with normal neurodevelopment ( $>4$ years) were asked to fill out the validated PedsQL 4.0 Generic Core Scales before and 3-4 months after LARS.
\end{abstract}

Femke A. Mauritz

femkemauritz@gmail.com

1 Department of Pediatric Surgery, Wilhelmina Children's Hospital, University Medical Center Utrecht, Room: KE.04.140.5, PO Box 85090, 3508 AB Utrecht, The Netherlands

2 Department of Pediatric Gastroenterology, Wilhelmina Children's Hospital, University Medical Center Utrecht, Utrecht, The Netherlands

3 Department of Gastroenterology and Hepatology, University Medical Center Utrecht, Utrecht, The Netherlands

4 Department of Biostatistics, Julius Center for Health Sciences and Primary Care, University Medical Center Utrecht, Utrecht, The Netherlands

5 Department of Pediatric Surgery, Maastricht University Medical Center, Maastricht, The Netherlands

6 Department of Pediatric Surgery, Sophia Children's Hospital, Erasmus MC, Rotterdam, The Netherlands
Results The PedsQL was completed by all caregivers $(n=25)$ and 12 children. HRQoL total score improved significantly after LARS, both from a parental $(p=0.009)$ and child's perspective $(p=0.018)$. The psychosocial health summary and physical health summary scores also improved significantly after LARS. HRQoL before and after LARS was significantly lower in children with impaired neurodevelopment $(p<0.001)$. However, neurodevelopment did not influence the effect of LARS on HRQoL. The only significant predictor for improvement in HRQoL after LARS was age at the time of operation $(p=0.001)$.

Conclusions HRQoL significantly improves after LARS. Although children with impaired neurodevelopment had lower overall HRQoL, neurodevelopment by itself does not predict inferior improvement in HRQoL after LARS. Older children have a more favorable HRQoL outcome after LARS compared to younger children. This may suggest caution when considering LARS in younger GERD patients.

Keywords Pediatric · Children · Reflux - GERD · Fundoplication · Quality of life · Antireflux surgery

Laparoscopic antireflux surgery (LARS) is an established treatment option performed in pediatric patients with severe gastroesophageal reflux disease (GERD) resistant to medical treatment $[1,2]$. LARS primarily aims to decrease (acid) reflux events and to reduce reflux symptoms. However, as shown in earlier studies the effect on reflux symptoms does not always correlate to more objective assessments of success of therapy [3, 4]. Furthermore, comorbidities (e.g., impaired neurodevelopment) and complications, such as dysphagia and gas-bloat syndrome [5], may also affect success of therapy. 
To better assess the impact of pediatric diseases and treatments from the perspective of the pediatric patient and their caregivers health-related quality of life (HRQoL), assessment has been increasingly recognized as an essential part of patient care outcome [6]. Effects of LARS on HRQoL have been mainly investigated in adult population. These studies almost all showed that HRQoL improves after LARS [7-9]. In the pediatric population, only few studies have focused on this outcome parameter [10-12]. HRQoL in these studies improves; however, none of these studies have used pediatric validated questionnaires. In two studies [10,11], a questionnaire designed for adults had been modified for pediatric use and one study had only used parental proxy report to score HRQoL [12]. Furthermore, none of these studies could identify determinants that influence HRQoL outcome after LARS. The Pediatric Quality of Life Inventory (http://www.pedsql.org.) 4.0 Generic Core Scales (PedsQL) is a reliable and valid tool (also for the Dutch language) for parental proxy report and parallel child's self-report on HRQoL. It has been used to assess HRQoL in children with numerous acute and chronic health conditions, as well as in healthy populations $[6,13-17]$. The aim of this study was to evaluate the effect of LARS on HRQoL using the PedsQL and to identify predictors that may influence HRQoL outcome after LARS.

\section{Patients and methods}

We performed a prospective multicenter study in three University Medical Centers in the Netherlands performing laparoscopic fundoplication in children (Wilhelmina children's Hospital, University Medical Center Utrecht (UMCU): Sophia children's Hospital, Erasmus University Medical Center (EMC) and Maastricht University Medical Center (MUMC). From July 2011 until December 2013, we prospectively included all pediatric patients diagnosed with PPI-therapy-resistant GERD. Patients that had undergone previous esophageal or gastric surgery (except previous gastrostomy placement) and those who had structural abnormalities other than an esophageal hiatal hernia were excluded.

\section{Patients}

In total, 25 children were included. Mean age of the included patients was six (range 2-18) years at the time of fundoplication (Table 1). Impaired neurodevelopment was present in $20 \%$ of patients $(5 / 25$ patients). Causes of impaired neurodevelopment are shown in Table 2.
Table 1 Baseline characteristics

\begin{tabular}{lc}
\hline & Median (IQR) \\
\hline Age at time of operation (years) & $6.0(3.0-11.0)$ \\
Duration of hospital admission (days) & $3.0(2.0-4.5)$ \\
\hline & $n(\%)$ \\
\hline Male gender & $12(48.0 \%)$ \\
Neurological normal development & $20(80.0 \%)$ \\
Gastrostomy preoperatively in situ & $4(16.0 \%)$
\end{tabular}

\section{Surgical procedures}

All laparoscopic fundoplications were performed by experienced pediatric surgeons in pediatric laparoscopic surgery. In the UMCU the anterior, partial fundoplication according to Thal [18] was used to perform fundoplication. In the other two UMC's (EMC and MUMC) the posterior, total fundoplication according to Nissen [19] was performed. Before fundoplication, the distal esophagus was fully mobilized; the distal $3 \mathrm{~cm}$ of the esophagus was repositioned back into the abdomen. Both vagal nerves were identified, and after dissection of both crura the hiatus was closed routinely (UMCU and EMC). Thereafter, the fundoplication was constructed. The Thal fundoplication was performed by plicating the fundus of the stomach over $270^{\circ}$ against the distal anterior intra-abdominal part of the esophagus and the diaphragmatic crus [3, 18]. A floppy Nissen was constructed with one of the sutures of the $360^{\circ}$ posterior wrap incorporated in the esophageal wall [19].

\section{Clinical assessment}

Before and 3 months after laparoscopic fundoplication, clinical assessment was performed using the PedsQL 4.0 Generic Core Scale for HRQoL, a reflux-specific symptom questionnaire, 24-h multichannel intraluminal impedance$\mathrm{pH}$ monitoring (MII-pH monitoring) and an 13C-labeled Na-octanoate breath test. Surgical re-interventions, type and indication for re-intervention, endoscopic procedures, complications, and comorbidities were registered in a prospective database.

1. Health-related Quality of Life-caregivers and children with normal neurodevelopment ( $>4$ years) were asked to fill out the 23-items PedsQL 4.0 Generic Core Scales [1, 14, 17, 19-21]. The scales are available for parental proxy report, subdivided in four age-adjusted questionnaires (ages: 2-4; 5-7; 8-12; and 13-18 years) and as a parallel child's self-report (ages: 5-7; 8-12; and 13-18 years). The PedsQL 4.0 Generic Core Scales comprises four domains: physical 
Table 2 Neurological impairment $(n=5)$

Charge syndrome
Mitochondrial complex II deficiency
Post-hypoxic encephalopathy
Congenital rubella infection
Neurologically impairment of unknown origin with autistic
behavior

functioning ( 8 items), emotional functioning ( 5 items), social functioning (5 items), and school functioning (5 items). With the four domains, the physical health summary score, the psychosocial summary score and the total score are calculated. The physical health summary score is reflected by the physical functioning scale. The psychosocial health summary score is reflected by the mean of the other three domains (emotional, social and school functioning). Scale scores per domain were computed as the sum of the items divided by the number of items answered. Thereafter, items were reversescored and transformed to a $0-100$ scale. Higher scale scores indicate better HRQoL.

2. Reflux-specific questionnaire-patients and/or their parents were asked to fill out the Gastroesophageal Reflux Symptom Questionnaire [22].

3. Ambulatory 24-h MII-pH monitoring-MII-pH monitoring was performed using an age-adjusted combined impedance-pH catheter (Unisensor AG, Attikon, Switzerland). Pathological acid exposure was defined as total acid exposure time $\geq 6, \geq 9 \%$ in upright, and $\geq 3 \%$ in the supine body position [23, 24]. The symptom index (SI) and the symptom association probability (SAP) was calculated when the patients experienced symptoms during measurement [25, 26].

4. Gastric emptying breath test-to assess gastric emptying time, we used a 13C-labeled Na-octanoate breath test [27]. Gastric emptying half time is defined as the time when the first half of the 13C-labeled substrate has been metabolized, that is, when the cumulative excretion of $13 \mathrm{C}$ in the breath is half the ingested amount. Gastric emptying percentiles were calculated according to the reference values obtained by van den Driessche et al. [28].

\section{Ethical approval and trial registration}

This study was registered at the start of the study in the Dutch national trial registry (www.trailregister.nl; Identifier: 2934). Ethical approval for this prospective multicenter study was obtained from the University Medical Center Utrecht Ethics Committee, and local approval was obtained by the remaining two participating centers. Prior to any trial-related study procedure, informed consent from the patients' parents and children ( $\geq 12$ years) was obtained.

\section{Statistical analysis}

Continuous variables, when symmetric, were expressed as mean \pm standard error. Skewed variables were expressed as median with interquartile ranges (IQR). For statistical analysis, we used the paired sample $t$ test or the Wilcoxon signed-ranks test. The McNemar-Bowker test was used to compare groups in case of nominal outcome measures. To assess the relationship between HRQoL and age at the time of operation, impaired neurodevelopment, reflux symptoms, acid exposure and gastric emptying, we used a linear mixed model with a random intercept per patient. A mixed model allowed us to analyze preoperative and postoperative measurements simultaneously, while taking into account correlation of measurements from the same subjects. Backwards selection was performed using the AIC. A linear regression analysis was performed to identify determinants influencing HRQoL and the effect of LARS on HRQoL. Determinant of interest included: age at the time of operation, impaired neurodevelopment, reflux symptoms, preoperative acid exposure time and preoperative gastric emptying rate. Differences with a $p<0.05$ were considered statistically significant. All analyses were performed using IBM $^{\circledR}$ 22.0.0 SPSS statistical package (IBM, Armonk, NY).

\section{Results}

In total, 18 Thal and 7 Nissen fundoplications were performed. In all patients, fundoplication was completed by laparoscopy. Perioperative complications were not observed. One patient with retching due to impaired neurodevelopment developed severe recurrent reflux caused by hiatal herniation that required re-fundoplication. In six children, temporary nasogastric tube feedings were required to obtain sufficient caloric intake. This was caused by transient dysphagia (dysphagia dissolved within 3-4 months after LARS; $n=4$ ), persistent dysphagia ( $>3-4$ months after LARS; $n=1$ ) or refusal of oral feedings $(n=1)$.

\section{Health-related quality of life}

The PedsQL was completed by all caregivers both before and after LARS for all included patients $(n=25)$. The HRQoL total score improved significantly after LARS from $69.8(57.2-80.1)$ to $82.0(69.3-89.2 ; p=0.009$; Fig. 1a). Twelve children were able to fill out the parallel 
self-report, and their total score also improved significantly from $72.6(7.4-82.3)$ to 84.6 (78.1-91.3; $p=0.018$; Fig. 1).

Furthermore, the psychosocial [54.2 (69.7-77.5) to 82.5 (72.9-89.6); $p<0.0001]$ and the physical health summary [75.0 (59.4-89.1) to $92.2(80.5-99.2) ; p<0.0001]$ also significantly improved for both caregivers as well as children's self-report after LARS (Figs. 2, 3).

Patients' self-report of overall HRQoL outcomes was significantly higher $(p=0.037)$ than parental proxy report before LARS; self-reported and proxy-reported HRQoL scores after LARS were not different.

\section{Reflux symptoms}

Reflux symptoms significantly decreased from 16 (64\%) patients with severe reflux symptoms before LARS to one (4\%) patient after LARS $(p=0.001)$. Deterioration of symptom severity or frequency was not seen in any of the patients. Dysphagia was reported in seven (28\%) patients before and in eight (32\%) patients after LARS ( $p=0.887)$. New-onset dysphagia was seen in three of these eight patients after LARS (Table 3).

Gastroesophageal functional assessment tests-total acid exposure decreased significantly from $8.5 \%$ (IQR 2.5-32.8) to $0.8 \%$ (IQR 0-21.6) after LARS ( $p<0.0001)$. Median gastric emptying rate before LARS (percentile 75, IQR 3-99) was similar to that after LARS (70, IQR 5-99, $p=0.530)$.

\section{PedsQI Total Score}

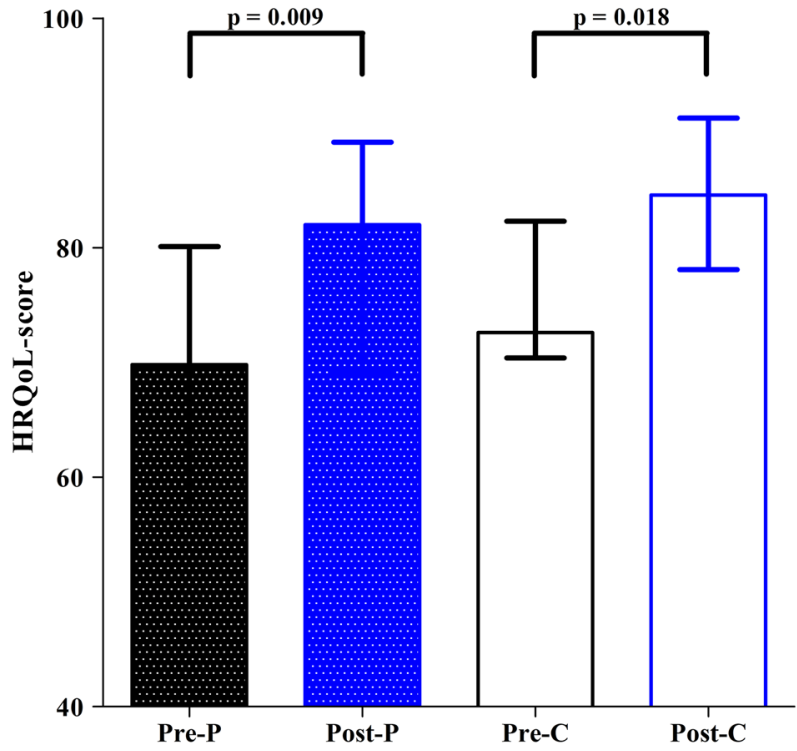

Fig. 1 HRQoL assessment using the PedsQL-total score (pre = before LARS; post $=$ after LARS; $P=$ parental proxy report; $\mathrm{C}=$ child's self-report)

\section{Psychosocial Health Summary}

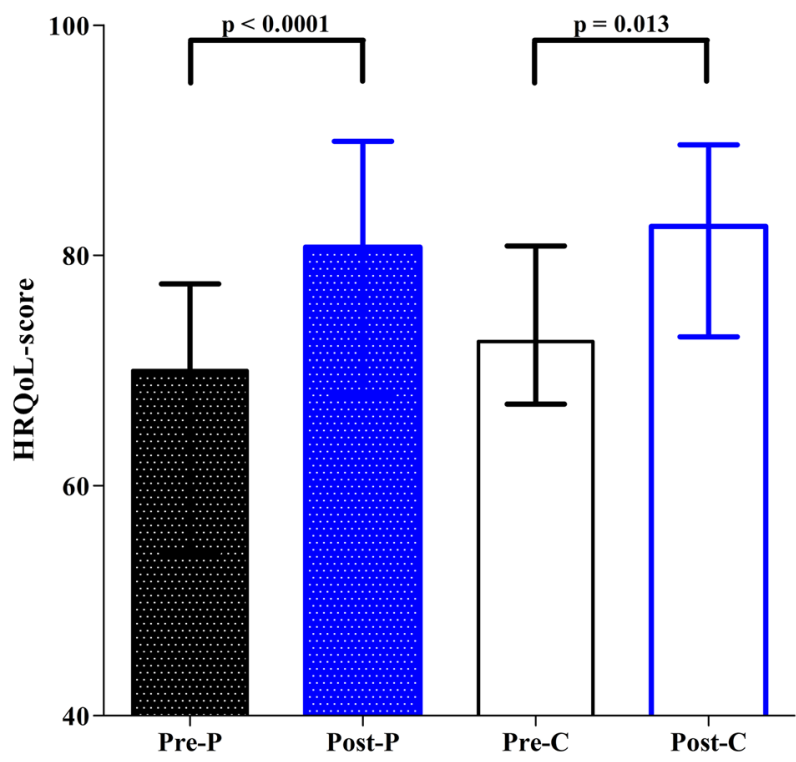

Fig. 2 HRQoL assessment using the PedsQ-psychosocial health summary $($ pre $=$ before LARS; post $=$ after LARS; $P=$ parental proxy report; $\mathrm{C}=$ child's self-report)

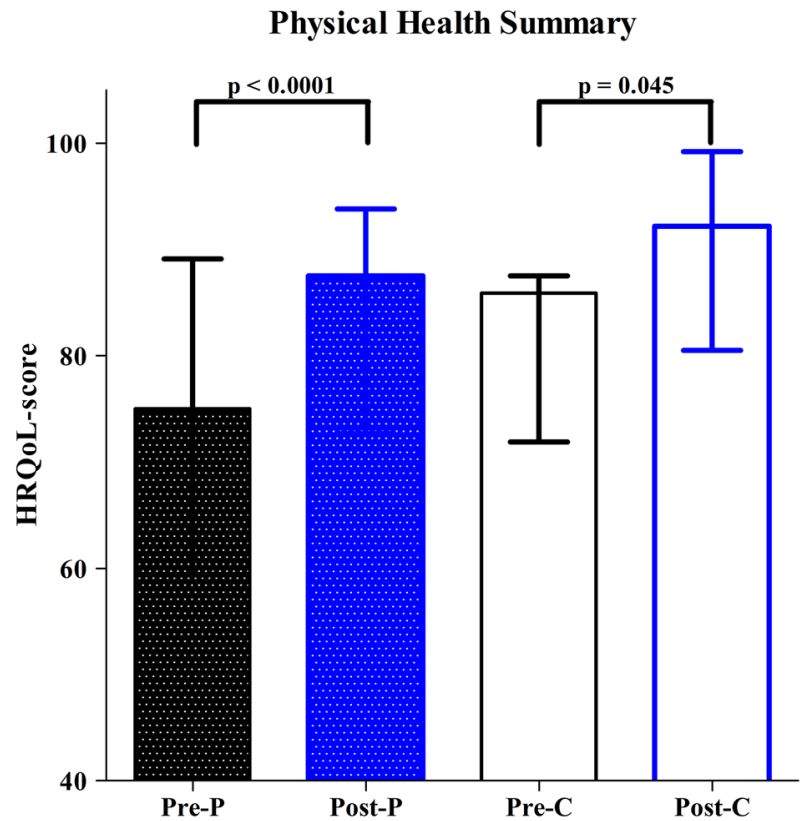

Fig. 3 HRQoL assessment using the PedsQL-physical health summary $($ pre $=$ before LARS; post $=$ after LARS; $P=$ parental proxy report; $\mathrm{C}=$ child's self-report)

\section{Factors influencing HRQoL}

Patients with impaired neurodevelopment (NI) had significantly lower HRQoL compared to patients with normal neurodevelopment (NN) (estimate 23.4; $p=0.006$; $(95 \%$ CI 7.2-39.5). Furthermore, reflux symptoms were also 
Table 3 Symptoms $(n=25)$

\begin{tabular}{lccc}
\hline & Preoperative $(n ; \%)$ & $3-4$ months postoperative $(n ; \%)$ & $p$ value \\
\hline Reflux symptoms & & & \\
No symptoms & $0(0 \%)$ & $17(68 \%)$ & 0.001 \\
Mild reflux symptoms & $2(8 \%)$ & $5(20 \%)$ & \\
Moderate reflux symptoms & $7(28 \%)$ & $2(8 \%)$ & 0.887 \\
Severe reflux symptoms & $16(64 \%)$ & $1(4 \%)$ & \\
Dysphagia & $7(28 \%)$ & $8(32 \%)$ & \\
\hline
\end{tabular}

negatively associated with lower HRQoL (estimate $=-4.31 ; p=0.006 ; 95 \% \mathrm{CI}-7.5$ to -1.3$)$. Age at the time of operation $(p=0.11)$, gastric emptying $(p=0.82)$ and total acid exposure $(p=0.75)$ did not significantly influence HRQoL.

\section{Predictors for the effect of LARS on HRQoL}

Linear regression analysis showed that an increase in age at the time of operation was a significant predictor for improvement in HRQoL after LARS ( $p=0.001$; estimate $=1.6$; 95\% CI 0.8-2.5; Fig. 4). Although HRQoL was significantly lower in NI children, neurodevelopment itself did not influence the change in HRQoL ( $p=0.73)$. Preoperative gastric emptying rate, total acid exposure time and reflux symptoms also did not significantly influence the change in HRQoL (Table 4).

\section{Discussion}

This is the first study on HRQoL in children undergoing LARS that used a validated pediatric HRQoL questionnaire [6, 13-17]. We demonstrate that after LARS HRQoL significantly increases and after LARS HRQoL scored were comparable to the normal HRQoL scores measured in a healthy population [13]. Furthermore, age at the time of operation is a significant predictor for improvement in HRQoL after LARS. Previous studies also showed a significant increase in HRQoL [10-12]. In two studies [10, 11], a questionnaire designed for adults had been modified for pediatric use and the third study only used parental proxy report. In contrast to these previous studies, this is the first study in pediatric LARS using a validated questionnaire for HRQoL. Using validated questionnaires in the pediatric population is important as results and questionnaires are not simply translatable for pediatric uses because pathophysiology, and patterns and symptoms of diseases may be different in children compared to adults [29]. Furthermore, this is the first study using both parental proxy reports as well as child's self-reports.

Some authors hypothesize that children with impaired neurodevelopment (NI) may not benefit to the same extent from LARS as those with normal development [30-32]. In the current study, overall HRQoL was significantly lower in NI children. However, the neurodevelopment itself did not influence the change in HRQoL. This indicates that while NI children with GERD had a lower overall HRQoL, LARS was equally effective regarding the change in HRQoL compared to children with normal neurodevelopment (NN). It is not surprising that NI children, who have more (co-) morbidity than NN children, scored lower in HRQoL; the PedsQL is able to distinguish between healthy children and pediatric patients with acute or chronic health conditions, and it is related to indicators of morbidity and illness burden [21].

The HRQoL scores of NI children for physical, social and school functioning were scored significantly lower compared to NN children. Emotional function, however, was not scored different from NN (data not shown). As NI children have more (co-)morbidities and associated disabilities they will likely score lower in physical and social functioning. The scores in the domain school functioning may be influenced by the possibility for caregivers or patients to leave these questions open if they are not applicable. If at least $50 \%$ is filled out in a specific domain, the score over that domain can, however, still be calculated. In the domain school functioning questions regarding attitude and performance at school were generally not filled out, whereas questions regarding presence/absence due to sickness or hospital visits were almost completely filled out by the caregivers.

Before LARS, children reported a significantly higher HRQoL than their parental proxies. This difference remained when only the child's self-report was compared to the score of their parents and the scores of the parents with children aged $<5$ or NI children were not taken into account. After LARS, this difference resolved as parents scored the HRQoL higher than children. It is not entirely clear why this difference in HRQoL resolves after LAR. We hypothesize that before LARS caregivers experience more burden from GERD on their child's HRQoL compared to their children's own perception. After LARS, GERD resolves in almost all children and it may therefore be possible that HRQoL assessments after LARS are therefore comparable. 
Fig. 4 Scatterplot illustrating difference in HRQoL comparing pre- to post-LARS HRQOL

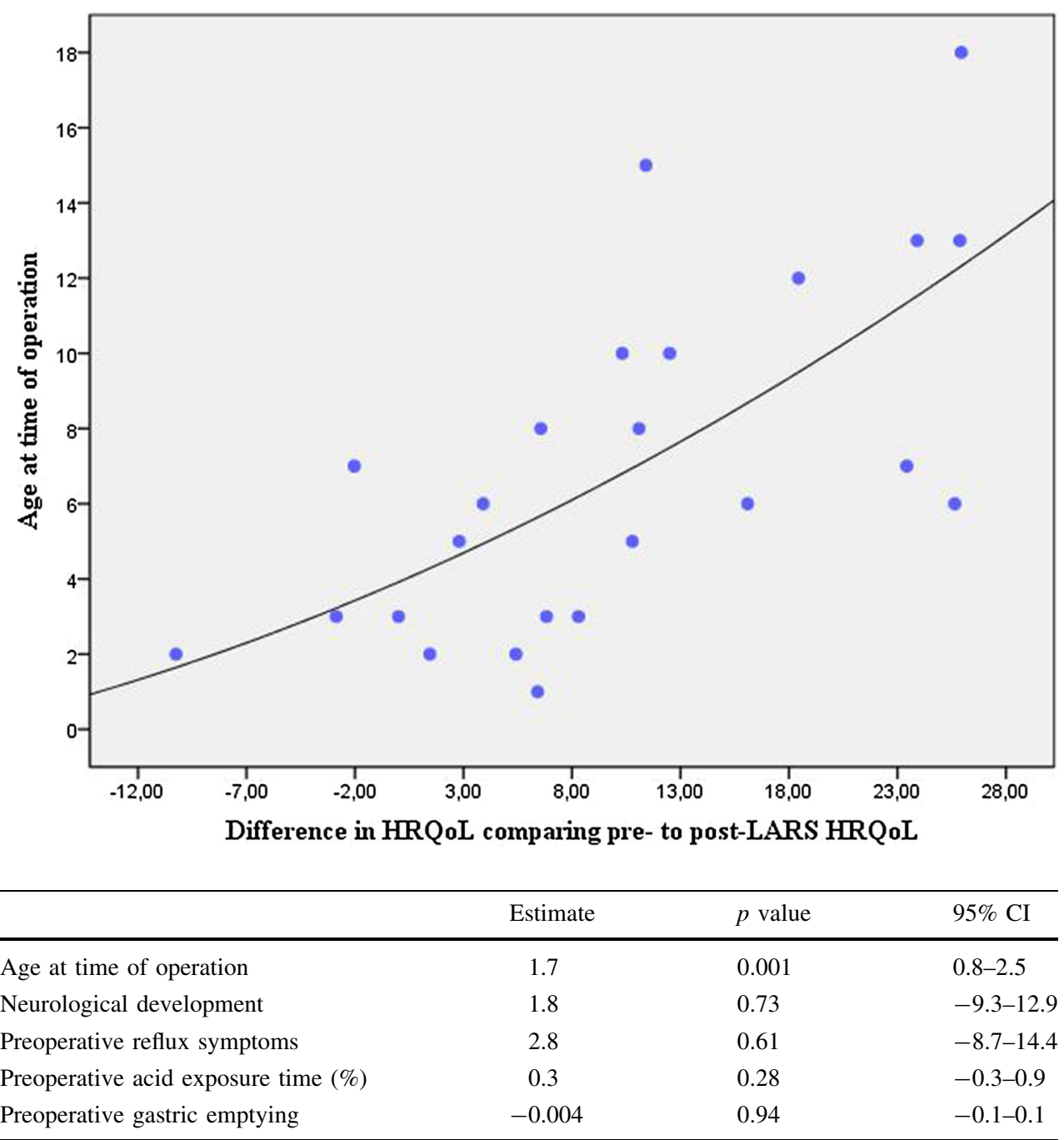

Linear regression analysis (95\% CI, 95\% confidence interval)
Various studies on HRQoL in children indicate that information provided by caregivers does not always correspond to what children report themselves [33, 34]. Pediatric patient self-report is considered to be the standard for measuring HRQoL, as it is the only genuine patientreported outcome [35]. It can, however, be difficult to obtain self-reports in young children and children with impaired neurodevelopment. In these cases, a parental proxy report may be the only way to assess HRQoL [36]. Furthermore, it has been shown that the parents' perception of their child's HRQoL influences health care utilization more than the perception of the child itself $[37,38]$.

Age at the time of operation was a statistically significant predictor of improvement in HRQoL after LARS. This means that LARS has more effect on HRQoL in older children and may suggest caution when younger children are referred for therapy-resistant GERD. It has been suggested that recurrence of GERD and even the necessity for redo-fundoplication are more frequently seen in young patients. These suggestions were based on two retrospective studies both using regression analysis to identify risk factors [39, 40]. Bearg et al. [39] showed that redo-fundoplication is significantly more frequent if patients are younger or have retching. Ngerncham et al. [40] reported that age less than 6 years was independently associated with increased risk of recurrence of GERD. Furthermore, it may also be possible that older children can specify their (reflux) complaints better, allowing a more precise diagnosis of therapy-resistant GERD to be made. Finally, it has been hypothesized that a young child may outgrow its fundoplication [4].

We initially hypothesized that preoperative gastric emptying might influence the success of LARS and thereby the effect on HRQoL as this has been shown in adult literature [41]. In this study, however, we did not find an effect of gastric emptying on HRQoL. 
It is plausible that reflux symptoms and acid exposure influence HRQoL assessment. In the current study, reflux symptoms were negatively associated with lower HRQoL. Remarkably, however, recurrence or persisting pathological acid exposure did not significantly influence HRQoL. It has been described before that reflux symptoms do not correlate to objective measurements of GERD, which may underscore the difficulty in symptom assessment [3, 4, 42].

One of the limitations in the current study was the limited number of 25 patients included. It was therefore only possible to investigate 5 determinants in linear regression assuming that we have sufficient statistical power with 5 patients per predictor. If more patients were included in this study, we would have had more power to detect the influence of these variables, and we had been able to investigate more potential determinants of changes in HRQoL. Secondly, this limited sample size, in addition to variations in surgical technique and multiple institutions, results to various forms of potential bias, such as confounding or type 2 errors. Furthermore, not all patients were able to fill out the self-report because of impaired neurodevelopment or age and as mentioned previously not all questions could be filled out by their caregivers, because in specific domains the questions were not always suitable when considering comorbidities and patient's limitations.

In conclusion, health-related quality of life, scored by both pediatric patients and their caregivers, significantly improves after LARS. Although patients with impaired neurodevelopment have lower overall HRQoL compared to neurologically normal developed patients, neurodevelopment itself is not a predictor of inferior improvement in HRQoL after LARS. Older children have a more favorable outcome of LARS on HRQoL compared to younger children. This suggests that with the diagnosis of therapy-resistant GERD in younger children, one should possibly be cautious to perform LARS.

Funding F.A. Mauritz is supported by an unrestricted research grant of the Wilhelmina Children's Hospital Fund and NutsOhra Fund. No other sources of support were used.

\section{Compliance with ethical standards}

Disclosures F. Mauritz, R. Stellato, L. van Heurn, P. Siersema, C. Sloots, R. Houwen, D. van der Zee and M. van Herwaarden-Lindeboom, have no conflict of interest or financial ties to disclose.

Open Access This article is distributed under the terms of the Creative Commons Attribution 4.0 International License (http://crea tivecommons.org/licenses/by/4.0/), which permits unrestricted use, distribution, and reproduction in any medium, provided you give appropriate credit to the original author(s) and the source, provide a link to the Creative Commons license, and indicate if changes were made.

\section{References}

1. Sherman PM, Hassall E, Fagundes-Neto U, Gold BD, Kato S, Koletzko S et al (2009) A global, evidence-based consensus on the definition of gastroesophageal reflux disease in the pediatric population. Am J Gastroenterol 104(5):1278-1295

2. Vandenplas Y, Rudolph CD, Di LC, Hassall E, Liptak G, Mazur L et al (2009) Pediatric gastroesophageal reflux clinical practice guidelines: joint recommendations of the North American Society for Pediatric Gastroenterology, Hepatology, and Nutrition (NASPGHAN) and the European Society for Pediatric Gastroenterology, Hepatology, and Nutrition (ESPGHAN). J Pediatr Gastroenterol Nutr 49(4):498-547

3. Mauritz FA, van Herwaarden-Lindeboom MY, Zwaveling S, Houwen RH, Siersema PD, van dZ (2014) Laparoscopic thal fundoplication in children: a prospective 10- to 15-year follow-up study. Ann Surg 259(2):388-393

4. van der Zee DC, Arends NJ, Bax NM (1999) The value of 24-h $\mathrm{pH}$ study in evaluating the results of laparoscopic antireflux surgery in children. Surg Endosc 13(9):918-921

5. Humphries LA, Hernandez JM, Clark W, Luberice K, Ross SB, Rosemurgy AS (2013) Causes of dissatisfaction after laparoscopic fundoplication: the impact of new symptoms, recurrent symptoms, and the patient experience. Surg Endosc 27(5):1537-1545

6. Ingerski LM, Modi AC, Hood KK, Pai AL, Zeller M, PiazzaWaggoner C et al (2010) Health-related quality of life across pediatric chronic conditions. J Pediatr 156(4):639-644

7. Dallemagne B, Weerts J, Markiewicz S, Dewandre JM, Wahlen C, Monami B et al (2006) Clinical results of laparoscopic fundoplication at ten years after surgery. Surg Endosc 20(1):159-165

8. Slim K, Bousquet J, Kwiatkowski F, Lescure G, Pezet D, Chipponi J (2000) Quality of life before and after laparoscopic fundoplication. Am J Surg 180(1):41-45

9. Velanovich V (2004) Using quality-of-life measurements to predict patient satisfaction outcomes for antireflux surgery. Arch Surg 139(6):621-625

10. Engelmann C, Gritsa S, Ure BM (2010) Impact of laparoscopic anterior 270 degrees fundoplication on the quality of life and symptoms profile of neurodevelopmentally delayed versus neurologically unimpaired children and their parents. Surg Endosc 24(6):1287-1295

11. Nicolau AE, Craciun M, Zota R, Kitkani A (2013) Quality of life after laparoscopic fundoplication for gastroesophageal reflux disease. Prelimin study. Chirurgia (Bucur) 108(6):788-793

12. Srivastava R, Downey EC, Feola P, Samore M, Coburn L, Holubkov R et al (2007) Quality of life of children with neurological impairment who receive a fundoplication for gastroesophageal reflux disease. J Hosp Med 2(3):165-173

13. Varni JW, Burwinkle TM, Seid M, Skarr D (2003) The PedsQL 4.0 as a pediatric population health measure: feasibility, reliability, and validity. Ambul Pediatr 3(6):329-341

14. Varni JW, Burwinkle TM, Seid M (2005) The PedsQL as a pediatric patient-reported outcome: reliability and validity of the PedsQL Measurement Model in 25,000 children. Expert Rev Pharmacoecon Outcomes Res 5(6):705-719

15. Varni JW, Burwinkle TM, Seid M (2006) The PedsQL 4.0 as a school population health measure: feasibility, reliability, and validity. Qual Life Res 15(2):203-215

16. Varni JW, Limbers CA, Burwinkle TM (2007) Parent proxyreport of their children's health-related quality of life: an analysis of 13,878 parents' reliability and validity across age subgroups using the PedsQL 4.0 Generic Core Scales. Health Qual Life Outcomes 5:2 
17. Varni JW, Limbers CA (2009) The pediatric quality of life inventory: measuring pediatric health-related quality of life from the perspective of children and their parents. Pediatr Clin North Am 56(4):843-863

18. Thal AP (1968) A unified approach to surgical problems of the esophagogastric junction. Ann Surg 168:542

19. Nissen R (1956) Eine einfache operation zur beeinflussung der refluxoesophagitis. Schweiz Med Wochenschr 86(20):590-592

20. Varni JW, Seid M, Rode CA (1999) The PedsQL: measurement model for the pediatric quality of life inventory. Med Care 37(2):126-139

21. Varni JW, Seid M, Kurtin PS (2001) PedsQL 4.0: reliability and validity of the pediatric quality of life inventory version 4.0 generic core scales in healthy and patient populations. Med Care 39(8):800-812

22. Deal L, Gold BD, Gremse DA, Winter HS, Peters SB, Fraga PD et al (2005) Age-specific questionnaires distinguish GERD symptom frequency and severity in infants and young children: development and initial validation. J Pediatr Gastroenterol Nutr 41(2):178-185

23. Richter JE, Bradley LA, DeMeester TR, Wu WC (1992) Normal 24-h ambulatory esophageal $\mathrm{pH}$ values. Influence of study center, pH electrode, age, and gender. Dig Dis Sci 37(6):849-856

24. Smout AJ, Breedijk M, van der Zouw C, Akkermans LM (1989) Physiological gastroesophageal reflux and esophageal motor activity studied with a new system for 24-hour recording and automated analysis. Dig Dis Sci 34(3):372-378

25. Omari TI, Schwarzer A, vanWijk MP, Benninga MA, McCall L, Kritas $S$ et al (2011) Optimisation of the reflux-symptom association statistics for use in infants being investigated by $24-\mathrm{h} \mathrm{pH}$ impedance. J Pediatr Gastroenterol Nutr 52(4):408-413

26. Weusten BL, Roelofs JM, Akkermans LM, Van Berge-Henegouwen GP, Smout AJ (1994) The symptom-association probability: an improved method for symptom analysis of 24-h esophageal $\mathrm{pH}$ data. Gastroenterology 107(6):1741-1745

27. Ghoos YF, Maes BD, Geypens BJ, Mys G, Hiele MI, Rutgeerts PJ et al (1993) Measurement of gastric emptying rate of solids by means of a carbon-labeled octanoic acid breath test. Gastroenterology 104(6):1640-1647

28. van den Driessche M, Ghoos Y, Veereman-Wauters G. Maturation of gastric emptying in healthy infants and children and reference values for the $13 \mathrm{C}$ octanoic acid breath test. Ref Type: Generic

29. Gold BD (2008) Comparing GERD manifestations in children and adults. Gastroenterol Hepatol (N Y) 4(1):40-44

30. Capito C, Leclair MD, Piloquet H, Plattner V, Heloury Y, Podevin G (2008) Long-term outcome of laparoscopic Nissen-
Rossetti fundoplication for neurologically impaired and normal children. Surg Endosc 22(4):875-880

31. Lobe TE (2007) The current role of laparoscopic surgery for gastroesophageal reflux disease in infants and children. Surg Endosc 21(2): 167-174

32. Kawahara H, Okuyama H, Kubota A, Oue T, Tazuke Y, Yagi M et al (2004) Can laparoscopic antireflux surgery improve the quality of life in children with neurologic and neuromuscular handicaps? J Pediatr Surg 39(12):1761-1764

33. Upton P, Lawford J, Eiser C (2008) Parent-child agreement across child health-related quality of life instruments: a review of the literature. Qual Life Res 17(6):895-913

34. Eiser C, Morse R (2001) Can parents rate their child's healthrelated quality of life? Results of a systematic review. Qual Life Res 10(4):347-357

35. Varni JW, Limbers CA, Burwinkle TM (2007) How young can children reliably and validly self-report their health-related quality of life?: an analysis of 8,591 children across age subgroups with the PedsQL 4.0 Generic Core Scales. Health Qual Life Outcomes 5:1

36. Hays RM, Valentine J, Haynes G, Geyer JR, Villareale N, McKinstry B et al (2006) The Seattle Pediatric Palliative Care Project: effects on family satisfaction and health-related quality of life. J Palliat Med 9(3):716-728

37. Campo JV, Comer DM, Jansen-Mcwilliams L, Gardner W, Kelleher KJ (2002) Recurrent pain, emotional distress, and health service use in childhood. J Pediatr 141(1):76-83

38. Janicke DM, Finney JW, Riley AW (2001) Children's health care use: a prospective investigation of factors related to care-seeking. Med Care 39(9):990-1001

39. Baerg J, Thorpe D, Bultron G, Vannix R, Knott EM, Gasior AC et al (2013) A multicenter study of the incidence and factors associated with redo Nissen fundoplication in children. J Pediatr Surg 48(6):1306-1311

40. Ngerncham M, Barnhart DC, Haricharan RN, Roseman JM, Georgeson KE, Harmon CM (2007) Risk factors for recurrent gastroesophageal reflux disease after fundoplication in pediatric patients: a case-control study. J Pediatr Surg 42(9):1478-1485

41. Rebecchi F, Allaix ME, Giaccone C, Morino M (2013) Gastric emptying as a prognostic factor for long-term results of total laparoscopic fundoplication for weakly acidic or mixed reflux. Ann Surg 258(5):831-836

42. Draaisma WA, Rijnhart-de Jong HG, Broeders IA, Smout AJ, Furnee EJ, Gooszen HG (2006) Five-year subjective and objective results of laparoscopic and conventional Nissen fundoplication: a randomized trial. Ann Surg 244(1):34-41 